\title{
A giant boring in a Silurian stromatoporoid analysed by computer tomography
}

Lydia Beuck, Max Wisshak, Axel Munnecke, and André Freiwald

Acta Palaeontologica Polonica 53 (1), 2008: 149-160 doi:http://dx.doi.org/10.4202/app.2008.0111

This study describes the largest known Palaeozoic boring trace, Osprioneides kampto igen. et isp. nov., found within a stromatoporoid Densastroma pexisum from the Upper Visby Formation (lower Wenlock, Silurian) on the island of Gotland, Sweden. Differences between the physical properties of the stromatoporoid and the dense micritic infilling of the borings allowed the application of the CT-scan technology for the 2D and 3D-visualisation of this rare trace. The additional application of a stereoscopic technique on these CT images and movies enhances its value for unravelling spatial orientations. This non-destructive method has a great potential for future macro- as well as microboring analyses. The trace maker, most likely a worm, infested the hosting colony post-mortem with up to $120 \mathrm{~mm}$ long borings measuring 5-17 mm in diameter. Smaller forms of Trypanites and Palaeosabella within the same stromatoporoid preferentially occur in the outer coenosteum and occasionally in abandoned borings of $O$. kampto. The stratigraphic position of $O$. kampto follows the 'Great Ordovician Biodiversification Event' in time, and reflects the increase in diversity of boring species. Borings with penetration depths of $120 \mathrm{~mm}$ are, however, unique findings for the Palaeozoic and were not exceeded until some 260 million years later (Bajocian, Middle Jurassic) when the 'Mesozoic Marine Revolution' led to convergent reinventions as a result of enhanced predation, grazing pressure, and ecospace competition.

Key words: Bioerosion, trace fossil, Osprioneides, stromatoporoid, computed tomography, Silurian, Gotland.

Lydia Beuck lydia.beuck@pal.uni-erlangen.de, Max Wisshak max.wisshak@pal.uni-erlangen.de , Axel Munnecke axel.munnecke@pal.uni-erlangen.de, and André Freiwald andre.freiwald@ pal.uni-erlangen.de, GeoZentrum Nordbayern, Fachgruppe Paläoumwelt, Friedrich-Alexander Universität Erlangen-Nürnberg, Loewenichstr. 28, D-91054 Erlangen, Germany.

This is an open-access article distributed under the terms of the Creative Commons Attribution License (for details please see creativecommons.org), which permits unrestricted use, 
distribution, and reproduction in any medium, provided the original author and source are credited.

Forif Full text $(1,089.4 \mathrm{kB})$ ।

Far) Supplementary file $(126.5 \mathrm{kB})$ 